\title{
Improving E-Learning by Integrating a Metacognitive Agent
}

\author{
Hanane Elbasri, Adil Haddi, Hakim Allali
}

LAVETE Laboratory, FST, Univ Hassan 1st, Settat, Morocco

\begin{tabular}{l} 
Article Info \\
\hline Article history: \\
Received Dec 22, 2017 \\
Revised Feb 15, 2018 \\
Accepted Mar 3, 2018 \\
\hline
\end{tabular}

Keyword:

Agent

Decision tree

Learning

LMS

Metacognition

\begin{abstract}
The major disadvantage of the current Learning Management Systems is the lack of learner assistance in their learning processes and, therefore, they can not replace the presence of the teacher who ensures the progress of learning. In fact, we proposed to integrate, for each learner, a metacognitive agent that supported the metacognitive assistance and extracts the defectsin the learning process and strategies. The goal is to invite the learner to correct himself and improve his learning method. Metacognitive questionnaires were distributed to a group of 100 students before, during and after a computer course. The goal is to evaluatethe metacognitive attributes and to determine their influence on the success of learning. Decision trees were used as data analysis tools to extract a set of rules and to discover the influence of these metacognitive attributes on the result obtained by the learners. The results indicate that there are relationships between the different metacognitive attributes and the learners' success. We note there is the influence of metacognitive incitement on learner outcomes, which reflects the degree of understanding of a learning pedagogical unit by the learner.
\end{abstract}

Copyright (c) 2018 Institute of Advanced Engineering and Science. All rights reserved.

\section{Corresponding Author:}

Hanane Elbasri, Lavete Laboratory, FST, Univ Hassan 1st, B.P.: 577, 26000, Settat, Morocco. Email: h.elbasri@uhp.ac.ma

\section{INTRODUCTION}

Flavell (1976) refers metacognition to a person's knowledge about his or her own cognition and about thecontrol he or she has over it [1]. On the other hand, Brown (1978) refermetacognitive skills to the planning, control,monitoring, and self-regulation activities that take place when learning and solvingproblems[2], [3]. Several studies indicate thatthe students' metacognition awarness is a widely used instructional strategy to enhance student learning [4]-[7]. Several works have tried to find the relationship between the components of metacognition skills, and the motivation or success of learning [8], [9]. Despite of the benefits of metacognition skills, its integration in learning management system can be a complex problem. In fact,several works have tried to integrate metacognitive skills into distance learning management platforms [10]-[13]. Raja M. (2016) used a conversational agents (chatbots) in Open Learner Models (OLM) to enhance learner model accuracy and provideopportunities for learner reflection [14]. Themistoklis (2012) propose the design of intelligent agent to support teachers in supervising and evaluating learners and activities [15].

In this paper, we propose to integrate an agent who encourages the learner to make a good planning, self-assessment, self-regulation and to determine the appropriate learning strategy by a dynamic dialogue system. In order to retrieve data on metacognitive skills and learner perception, we used the forms in a dynamic dialogue system from the beginning to the end of reading a learning pedagogic unit. The agent receives real-time feedback from the learner via these forms and records the answers for a later analysis by means of decision tree. This analysis allows us to find the rules that linked metacognitive skills to the state (disoriented, confused and imprudent) of a learner. 
The absence of the teacher requires the learner to cope with the learning process without a guide and orientation. To support and guide learners to succeed learning and avoid the high dropout rate observed [16], in this study, the agent triggers a series of incentives before, during and after reading a course. These incentives are done at predefined times or automatically based on the rules and learner perception. We find that the result of the learners who provide metacognitive assistance is better.

The paper is organized as follows. Section 2 covers metacognitive skills. Section 3 describes the Multi Agents systems characteristics. In Section 4, we present the assessment and data analysis methodology. Next, in Section 5 we present result and discution in a real case study. In Section 6, we present our conclusions and perspectives.

\section{RELATED WORKS}

Encouraging learners to think in metacognitive terms should have a positive impact on learning performance, which is confirmed by the results obtained in 2007 by Maria Bannert [11]. In 2009, a relationship was found between self-assessment on the one hand and the effort and performance of learners on the other hand by Izaskun Ibabe [5]. In 2012, Nilgün and his team studied the effect of integrated computer-assisted learning on metacognitive incentives on students' emotional skills [8]. In 2013, Long and Aleven argued that self-evaluation and study choice are two important metacognitive processes involved in self-regulated learning [17].

The relationship between executive functions (inhibitory control and memory work) and metacognitive skills was studied in 2014 by Donna Bryce [18]. In 2017, Christina Juliane said that motivation is undeniable for the success of e-learning processes [19]. In the same year, a relationship was found between learning styles and learner behavior in online learning by Baharudin and his team [20]. Indeed, metacognition can take many forms. It includes knowledge of when and how to use learning strategies [21]. All the work that has been done shows the impact of a metacognition skill on the learners' performance or the success of the training. However, no work addresses the relationship between metacognitive skills and learner status.

In this article, we determine the possible relationships between metacognitive skills and learner states. Indeed, we present an agent model that can motivate a learner to use skills based on his state. The agent uses a set of rules and actions to develop the metacognitive skills of the learners. The rules are extracted using the decision tree.

\section{METACOGNITION SKILLS}

The position in this paper is consistent with thewidely-held view that metacognition refers to the knowledge, control and awareness that students possess in relation to their thinking and learning processes [22]. According to Flavell [22], metacognition is defined as the ability to reflect on and control one's own cognitive processes which includes knowledge of the 'why', the 'how' and the 'when', the learner thus engaging in various cognitive activities.Metacognition has the following three main phases:

a. the planning phase: allows the learner to organize how he or she will use the information, ie define hisor her goals, ask himself questions before reading a lesson;

b. the control phase: allows the learner to make decisions that aim to control the degree of comprehension and manage the learning process, ie focus attention, evaluate during reading, maintain motivation, etc .;

c. the self-regulation phase: allows the learner to focus on activities that are strongly related to control such as decreasing reading speed, changing the learning strategy adopted to adjust to the difficulty of the course, etc.

\section{THE METACOGNITIVE AGENT}

Agents are software or hardware elements that operate within an environment, act and sense, andcommunicate and collaborate with other elements [23]. Every agent follows goals or tasks which are specified in the next section [24].

\subsection{The agents' roles}

In this study, the agent deals with metacognitive assistance. It reacts according to learners' feedback and association rules extracted by an analysis of data that we have previously collected from students. In fact, the agent stimulates learners who need help and offers them metacognitive support in their learning that shows in Table 1. 
Table 1. The Stimulation Performed by the Agent at each Learning Phase [25]

\begin{tabular}{ll}
\hline Learning Phases & Stimulation \\
\hline Planning & Establish the purpose, time and strategy of learning \\
Control & Control thet learning assessment \\
Regulation & Adjust the learning plan and strategy \\
\hline
\end{tabular}

In this paper, we propose a model of metacognitive agent that collects feedbacks [26], [27] (questionnaire, interactions) of learners to measure and evaluate their experiences and their metacognitive skills. In this respect, we offer learners a space to take notes, keywords and difficult concepts, as well as we require a formative evaluation on the educational support content. We record all their actions and answers in order to analyze them by the agent. It aims to determine how and when the agent can intervene to encourage learners to improve their learning method that shows in Figure 1.

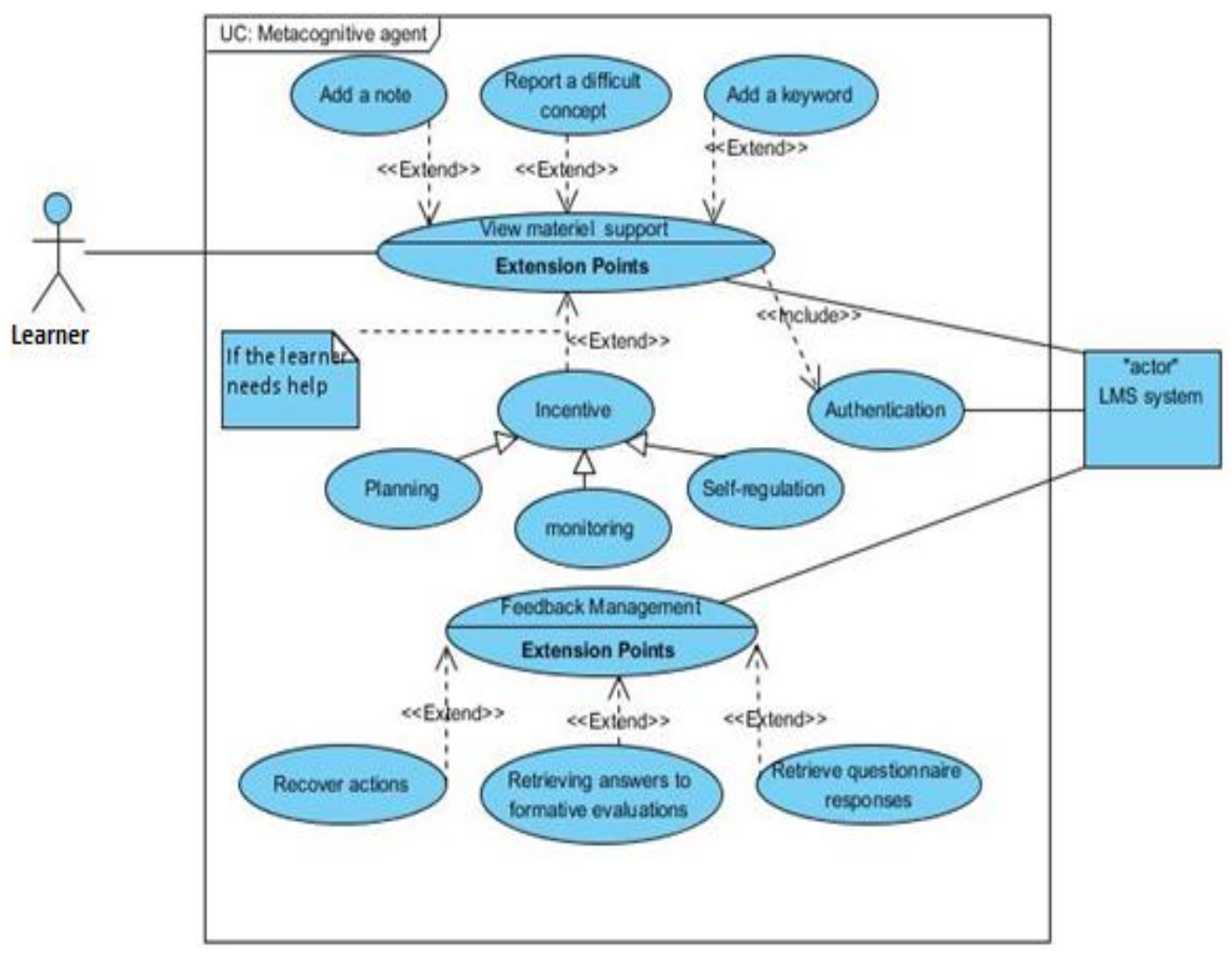

Figure 1. Use case diagram of the metacognitive agent

\subsection{The agent's activity diagram}

The following diagram shows the triggers of the metacognitive agent in each metacognitive phase at a specific time in a learning environment.The agent uses the forms in a dynamic dialogue system from the beginning to the end of reading a learning pedagogical unit. The agent receives real-time feedback from the learner via these forms and records the answers for a later analysis by means of decision tree. This analysis allows us to find the rules that linked metacognitive skills to the state (disoriented, confused and imprudent) of a learner. The agent record all learner's actions and answers in order to analyze them. It aims to determine how and when the agent can intervene to encourage learners to improve their learning method that shows in Figure 2. In the case where the learner has learning difficulties or has a bad grade, the agent encourages him to use the metacognitive skills. 


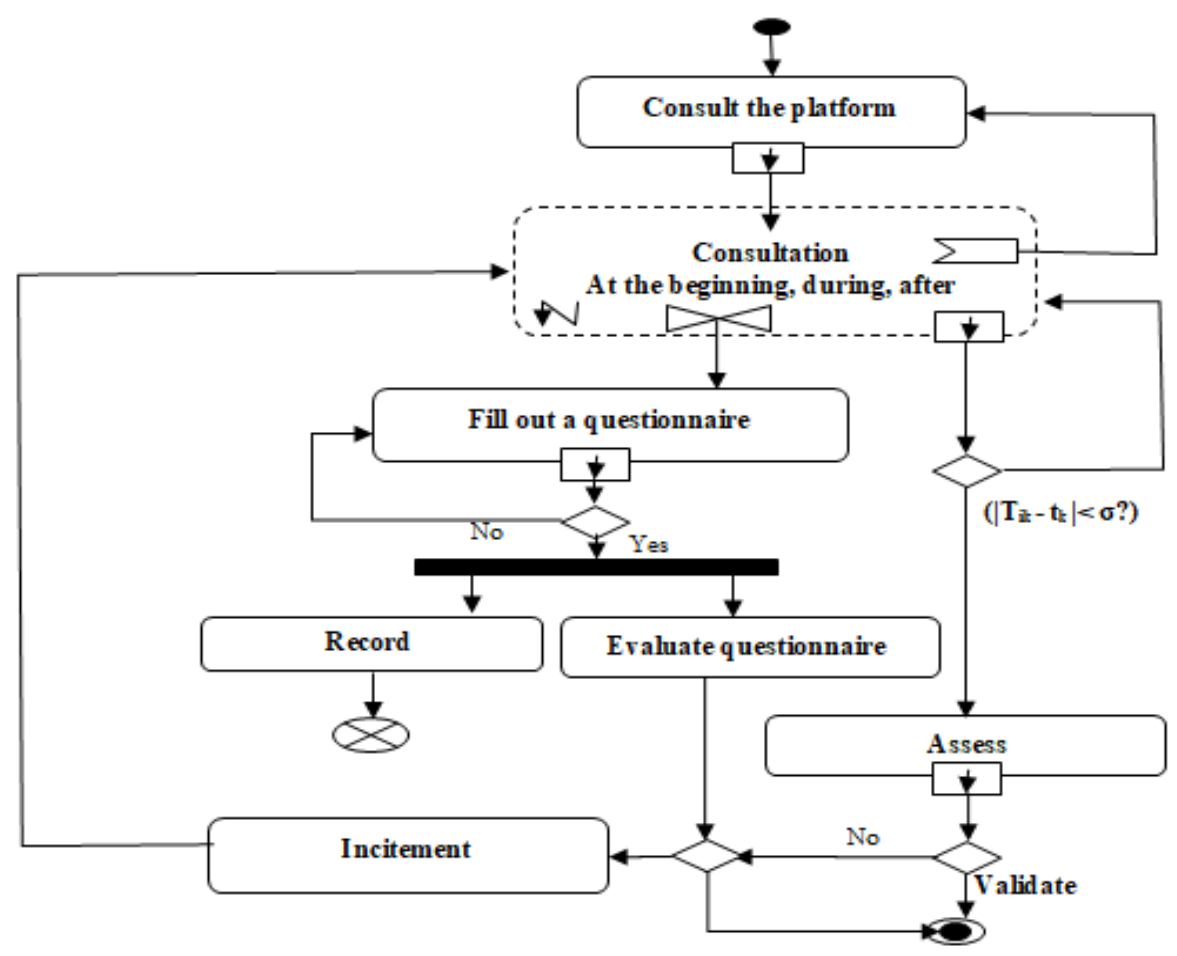

Figure 2. Activity diagram of metacognitive incentives and learning environment

\section{METHODOLOGY}

The variables are divided into a set of metacognitive attributes. The purpose of this work is to examine the effect of these metacognitive attributes on the quality of distance learning and on learner autonomy in order to stimulate the learner in online learning situations. In this section, we will present the method of evaluation of the following metacognitive variables:

a. planning: evaluate the degree of organization of the learner,

b. strategies: assess the learner's metacognitive knowledge,

c. self-assessment: assess whether the learner controls the method adopted in his / her learning ;

d. self-regulation: assess the learner's ability to change the strategy in the case of learning difficulty.

The documentation used to collect data conists of a pedagogical unit and questionnaire. We integrate in each unit, which has one or more objectives, questions (at the beginning, in progress and at the end) on the metacognitive variables that shows in Figure 3. After reading pedagogical unit and filling in the questionnair we distribute evaluation test on the content of the pedagogical unit and the perception of the learners. The data was collected from a group of 100 students from the Faculty of Science and Technology of Settat (Morocco, North Africa).

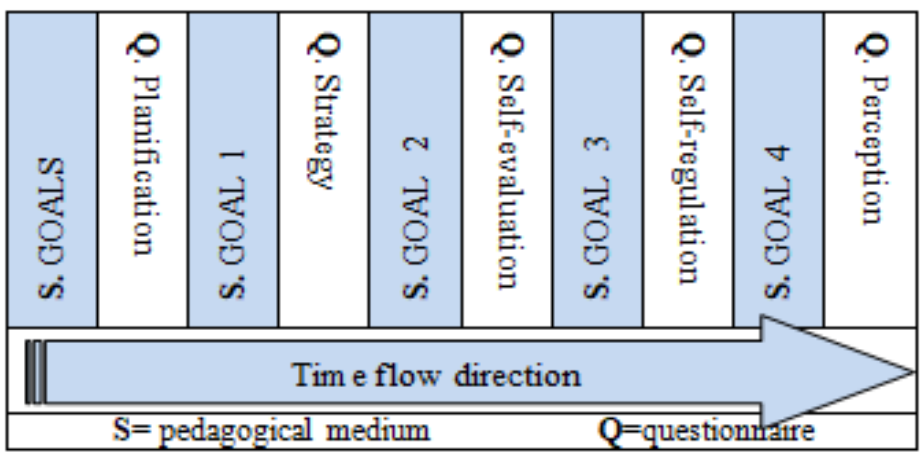

Figure 3. Structure of documents used to collect data 


\subsection{Assessmentof metacognitive variables}

To evaluate each metacognitive variable, we used a set of questions that have two possible answers, "yes" or "no". Each answer has an elementary note "1" or "-1" that will be used to determine the overall score. The overall score is calculated from the sum of the elementary scores divided by the number of questions. Thus, the overall score will be between "-1" and "1". In our study, we were satisfied with giving a "yes" value to a metacognitive variable if the overall score is greater than zero, otherwise it is assigned the value "no". For the evaluation of the planning procedure, the following formula is used:

\section{planning $=$ if $($ total $($ planning $)<0)$ : no: yes}

The same formula is used for all other characteristics, namely "strategy", "self-evaluation", "selfregulation ", etc. The data relating to the variables are collected via the questionnaire whose structure and nature are summarized in the Table 2.

Table 2. Structure and Nature of the Question

\begin{tabular}{|c|c|c|c|c|}
\hline Planification & Strategy & Self-evaluation & Self-regulation & Perception \\
\hline $\begin{array}{l}\text { 1- Goals } \\
\text { 2- Choice of the place, use of } \\
\text { time, concentration } \\
\text { 3-Interest for the course structure } \\
\text { 4-Use of tables, diagrams, etc. }\end{array}$ & $\begin{array}{l}\text { 1- Use of questioning to } \\
\text { understand, memorizing } \\
\text { the key terms } \\
\text { 2- Identification of the } \\
\text { main ideas and the } \\
\text { preparation of summary } \\
\text { 3-Relationships with } \\
\text { other courses and other } \\
\text { concepts } \\
\text { 4-Use of "backtracking" } \\
\text { in case of non- } \\
\text { understanding } \\
\text { 5-Transition from } \\
\text { "easy" to "difficult", } \\
\text { from "simple" to } \\
\text { "complicated" }\end{array}$ & $\begin{array}{l}\text { 1- Cours } \\
\text { understanding } \\
\text { 2- Identification } \\
\text { of the no } \\
\text { understand } \\
\text { concepts }\end{array}$ & $\begin{array}{l}\text { 1- Change of } \\
\text { learning method } \\
\text { 2- Use of help } \\
\text { 3-Adaptation to } \\
\text { the requirements } \\
\text { of the course. }\end{array}$ & $\begin{array}{l}\text { 1 Imprudence } \\
\text { 2-Disorientation } \\
\text { 3-Confusion } \\
\text { 4-Success }\end{array}$ \\
\hline
\end{tabular}

\subsection{The association rules between metacognitive variables and the learners perception}

The decision tree that shows in Figure 5, generated from the data collected, shows that there is a great deal of dependence between the use of metacognitive strategies (planning, self-evaluation, selfregulation and learning strategies) by a learner and his or her perception state (disoriented, confused and imprudent). Indeed, we have extracted the following rules:

a. if not (planning), then the learner is disoriented;(1)

b. if not (self-evaluation) and not (self-regulation), then the learner is confused;(2)

c. if not (learning strategies), then the learner is imprudent. (3)

d. if not (planning) and not(self-regulation) and not (memorization strategies) then unsuccess (4)

We used the previous rules to define the actions to be taken by the metacognitive agent in the case where a learner has a problem during his learning process that shows in Table 3.

Table 3. Association between States and Actions to be Performed by the Metacognitive Agent

\begin{tabular}{ll}
\hline \multicolumn{1}{c}{ State } & \\
\hline Disoriented & Encourage planning \\
Confused & Encourage the use of self-assessment strategies and self-regulation strategies \\
Imprudent & $\begin{array}{l}\text { Encourage the use of metacognitive strategies, and links between concepts and } \\
\text { teaching units }\end{array}$ \\
unsucssess & Encourages the learner to planning, self-regulation and memorization strategies
\end{tabular}

\subsection{Integration of the learners metacognitive help}

We assume that pedagogical support is an orderly sequence of pedagogical units and each learner must validate previous unit to learn the next one that shows in Figure 4. Otherwise, the agent performs the learner's metacognitive (planning, metacognition strategies, self-evaluation and self-regulation) incentive 
according to learner's perception (confused, imprudent and disorderly). The agent encourages learners whom have the learning disabilities to use metacognitive strategies.

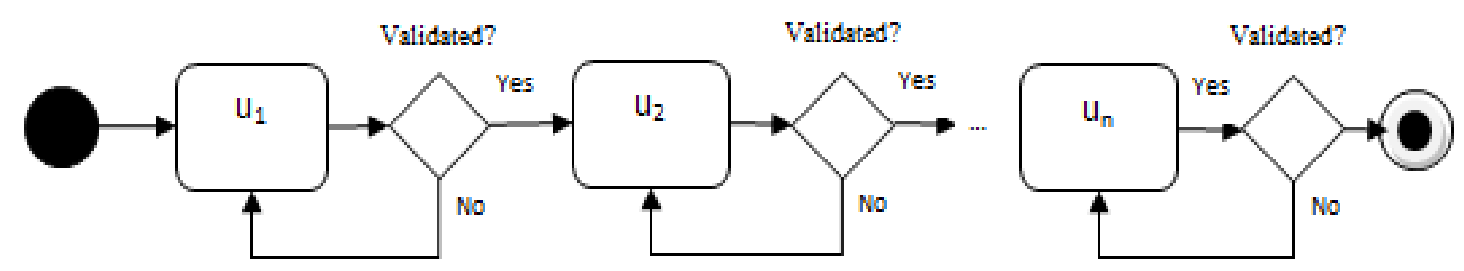

Figure 4. Structure of learning support

\subsection{Notation}

$\left(\mathrm{u}_{\mathrm{k}}\right)_{\mathrm{k}=1 \ldots \mathrm{n}}$ : a sequence of pedagogical units which composes a pedagogical support S. Each pedagogical unit $u_{k}$ is characterized by its pedagogical goals, the minimum note $n_{k}$ to validate and the consultation time $t_{k}$ and the tolerance $\sigma$ predefined by the teacher. $\left(a_{i}\right)_{i=1 \ldots m}$ : is a community of learners concerned by the consultation of the same pedagogical medium $\mathrm{S}$.

$\mathrm{T}_{\mathrm{ik}} \mathrm{etN} \mathrm{N}_{\mathrm{ik}}$ : the consultation time of pedagogical support and the score obtained by learner $\mathrm{a}_{\mathrm{i}}$ in the pedagogical unit $\mathrm{u}_{\mathrm{k}}$.

In the case where the learner has not invested sufficient time $\left(\mathrm{T}_{\mathrm{ik}}<\mathrm{t}_{\mathrm{k}}-\sigma\right)$ and consequently less effort, the agent evaluates the motivation and attention of the learner based on the answers to questions. If the level of motivation is low, the agent triggers incentives to motivate and make the learner more active and cautious. Otherwise, the agent encourages the learner to review the goals and reschedule the learning.

In the case where $\left(T_{i k}>t_{k}+\sigma\right)$ and the learner doesn't leave the learning - in other words, the learner finds difficulties or loses motivation - the agent asks the learner: "do you find difficulties? ".Depending on the learner's response, the agent will trigger incentives to motivate and make the learner more active and cautious if the answer is negative. Else, the metacognitive agent perceives the state $S_{t i}$ of the learner $a_{i}$ at a time t.Sti can have the following values: confused, disoriented or imprudent. The agent associates each state with an Act $_{\mathrm{ti}}$ action (incentive associated with the $\mathrm{S}_{\mathrm{ti}}$ state in Table 3). In the case where the consultation time is in the standards $\left(\left|\mathrm{T}_{\mathrm{ik}}-\mathrm{t}_{\mathrm{k}}\right|<\sigma\right)$ :

a. if the learner has sufficient confidence in himself / herself, he / she may pass the assessment test to validate the learning unit $\mathrm{u}_{\mathrm{k}}$; otherwise the agent encourages him / her to use the self-assessment and selfregulation strategies; (rule 2);

b. if the learner has a $\mathrm{N}_{\mathrm{ik}}$ rating higher than the validation score $\mathrm{n}_{\mathrm{k}}$, he can move on to the next pedagogical unit; otherwise, the agent encourages the learner to planning, self-regulation and memorization strategies that promote successful learning. These strategies are effectively used by learners who have passed with successfullythe unit in question (rule 4).

\section{RESULT AND DISCUSSION}

The decision tree shows that there is a relationship between the learner's state and his metacognitive skills that shows in Figure 5. By exploiting the state of the learner, the agent generates interesting motivations in natural language, which 'leads the learner to improve his metacognitive skills. To do this, our study focuses, first, on managing the dialogue between the agent and the learners for negotiation and, then, focuses on the effects of our agent on the metacognitive skills of learners. We observe that the percentage of learners who have successfully completed the learning is greater $(71 \%)$ with the integration of the metacognitive agent than without this agent (30\%) that shows in Table 4. Indeed, the result shows the importance of the metacognitive agent in the learning process.Indeed, metacognitive incentives allow learners to become aware of their mental processes and to improve their learning method. Therefore, the learner who has the metacognitive skills easily succeeds in the learning task that shows in Figure 6. 


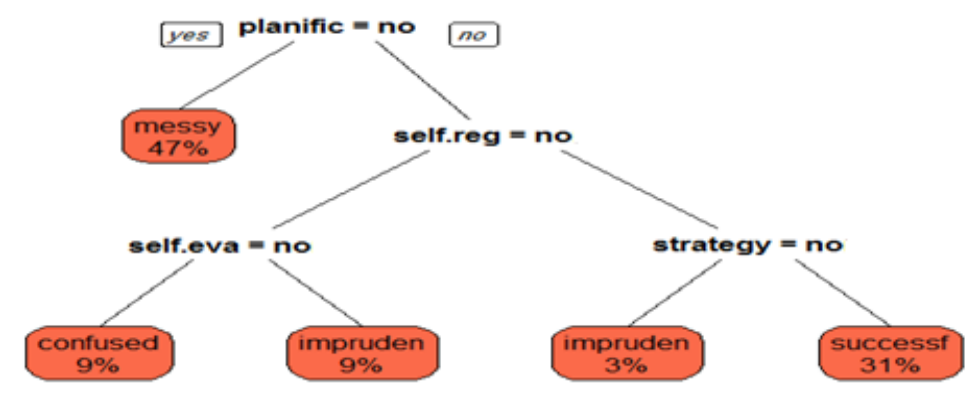

Figure 5. Tree induced on real data with a predicted value "state"

Table 4. The Rules of the Decision Tree

1. If planning $=$ no, then the learner is in a messy (disoriented) state.

2. If planning $=$ yes and self-regulation $=$ no and self-assessment $=$ no, thenthe learner is in a state of confusion.

3. If (planning $=$ yes and self-regulation $=$ no and self-assessment $=$ yes $)$ or $($ planning $=$ yes and self-regulation $=$ yes and strategy $=$ no), then the learner is in a state of recklessness.

4. If (planning = yes and self-regulation = yes and strategy = yes), then the learner is successful.

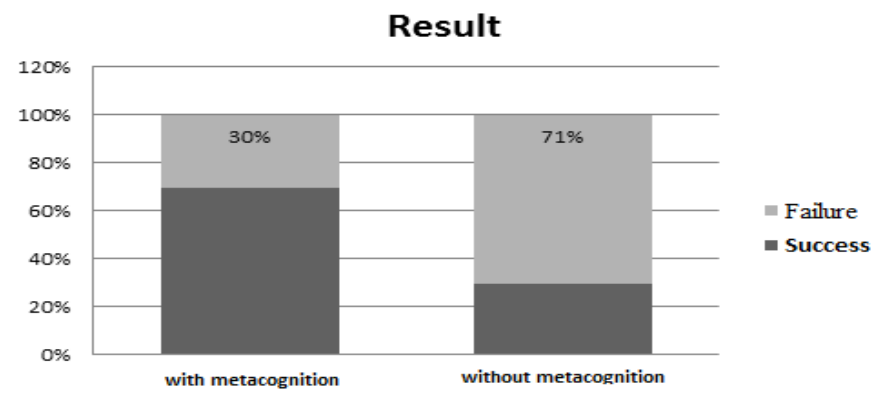

Figure 6. Comparison of learners' results with and without the use of metacognition

\section{CONCLUSION AND PERSPECTIVES}

This study was conducted to examine the effect of different metacognitive variables on the success of the learning process. The result obtained shows that the integration of a metacognitive agent into the distance learning management system can significantly improve metacognitive skills and knowledge. The main goal of our study is to encourage the learner to use metacognitive skills in their online learning process. The result shows that the influence of the metacognitive agent on the e-learning process is important because it develops the learner's autonomy, maintains his or her intention and motivation, helps him or her to acquire metacognitive skills such as planning, self-assessment, self-regulation, techniques and memorization strategies. In a future work, we intend to build a standard metacognitive agent model that can communicate with the LMSs and base the rules dynamically extract. We will improve its functioning so that it can automatically detect the state and profile of the learner and react in real time.

\section{REFERENCES}

[1] Flavell, J. H., "Metacognitive Aspects of Problem Solving", The nature of intelligence, New Jersey, pp. 231-235, 1976.

[2] Brown, A. L.. Hillsdale, NJ: Erlbaum., "Knowing When, Where, and How to emember : A Problem of Metacognition", Advances In Instructional Psychology, pp. 77-165, 1978.

[3] Mohd Rum, S. N., and Ismail, M. A., "Metocognitive Support Accelerates Computer Assisted Learning for Novice Programmers", Educational Technology \& Society, vol. 20, no. 3, pp. 170-181, 2017.

[4] Anderson, et al., "Changing the Metacognitive Orientation of a Classroom Environment to Enhance Students' Metacognition Regarding Chemistry Learning", Learning Environ Res, Springer ScienceBusiness Media Dordrecht, pp. 139-155, 2013.

[5] Jauregizar and Izaskun Ibabe Æ Joana, "Online Self-assessment with Feedback and Metacognitive Knowledge", High Educ ,Springer Science+Business Media. 2010, pp. 243-258, 2010. 
[6] Ryu, et al., "The Development and Implementation of a Web-based Formative Peer Assessment System for Enhancing Students' Metacognitive Awareness and Performance in Ill-structured Tasks", Education Tech Research Dev, pp. 549-561, 2013.

[7] Bernard, M., and Bachu, E. "Enhancing the Metacognitive Skill of Novice Programmers through Collaborative Learning”, In Metacognition: Fundaments, Applications, and Trends, pp. 277-298, 2015.

[8] Feyzioglu, et al., "The Effect of Computer-Assisted Learning Integrated with Metacognitive Prompts on Students' Affective Skills", J Sci Educ Technol, Springer Science Business Media. New, 2012.

[9] Aleven, et al., "Supporting Students' Self-Regulated Learn with an Open Learner Model in a Linear Equation Tutor”, AIED, LNAI 7926, Springer-Verlag. Berlin Heidelberg, pp. 219-228, 2013.

[10] Szücs, et al., "The Relationships among Executive Functions, Metacognitive Skills and Educational Achievement in 5 and 7 year-old children", Metacognition Learning, Springer Science+Business, pp. 181-198, 2014.

[11] Maria Bannert and Christoph Mengelkamp, “Assessment of Metacognitive Skills by Means of Instruction to think aloud and reflect when prompted Does the Verbalisation Method Affect Learning", Metacognition Learning, Springer Science + Business Media, pp. 39-58, 2007.

[12] Steffens, et al., "Research on Self-Regulated Learning in Technology Enhanced Learning Environments: Two Examples from Europe", International Handbook of Metacognition and Learning Technologies, Springer International Handbooks of Education 26, New York, 2013.

[13] Veenman and Marcel V. J., "Assessing Metacognitive Skills in Computerized Learning”, International Handbook of Metacognition and Learning Technologies, Springer ScienceBusiness Media, New York, pp. 157-168, 2013.

[14] .Raja M. Suleman, et al., "A New Perspective of Negotiation-Based Dialog to Enhance Metacognitive Skills in the Context of Open Learner Models”, International Artificial Intelligence in Education Society, pp. 1069-1115, 2016.

[15] Hatzilygeroudis, et al., "The Design of a Teacher-Driven Intelligent Agent System for Supervising Lessons in LAM”, Intelligent Adaptation \& Personalization Techniques, Springer-Verlag Berlin Heidelberg, pp. 211-238, 2012.

[16] Clément Dussarps, "L'abandon en formation à distance", Distances et médiations des savoirs ,http://dms.revues.org/1039, 2017.

[17] Long Y and Aleven V, "Supporting Students' Self-Regulated Learning with an Open Learner Model in a Linear Equation Tutor", Artificial Intelligence in Education, 16th International Conference, AIED 2013, vol. 7926, pp. 219-228, 2013

[18] Bryce D, et al., "The Relationships among Executive Functions, Metacognitive Skills and Educational Achievement in 5 and 7 year-old children", Metacognition Learning, 2014.

[19] Juliane C, et al., "Predicting the presence of learning Motivation in Electronic learning : A New Rules to Predict", TELKOMNIKA (Telecommunication, Computing, Electronics, and Control), vol. 15, no. 3, pp 1223-1229, 2017.

[20] Baharudin A. F., et al., "Behavioral tracking in E-learning by using Learning styles approach", IJEECS, vol. 8, no. 1, pp.17-26, October 2017.

[21] Metcalfe J., and Shimamura A, "Metacognition: Knowing About Knowing”, Bradford Books, Cambridge, 1994.

[22] Flavell, J. H., "Metacognition and Cognitive Monitoring: A New Area of Cognitive-developmental Inquiry", American Psychologist, vol. 34, no. 10, pp. 906-911, 1979.

[23] Hamid B., et al., "Architectural Approaches for Self-Healing Systems Based on Multi Agent Technologies", International Journal of Electrical and Computer Engineering (IJECE), vol. 3, no. 6, pp. 779-783, 2013.

[24] Lotfi E., et al., "Towards a System of Guidance, Assistance and LearningAnalytics Based on Multi Agent System Applied on SeriousGames", International Journal of Electrical and Computer Engineering (IJECE), vol. 5, no. 2, pp. 344-354, 2015.

[25] Hamid B., et al., "Multi-Agent Approach for Facing Challenges in Ultra-LargeScale systems", International Journal of Electrical and Computer Engineering (IJECE), vol. 4, no. 2, pp. 151-154,2014.

[26] Gregg Dawn G, "E-learning Agents", The Learning Organization, vol. 14, no. 4, pp. 300-312, 2007.

[27] Arief Hidayat, Victor Gayuh Utomo, "Adaptive Online Module Prototype for Learning Unified Modelling Language (UML)", International Journal of Electrical and Computer Engineering (IJECE), vol. 6, no. 6, pp. 2931-2938, 2016.

\section{BIOGRAPHIES OF AUTHORS}

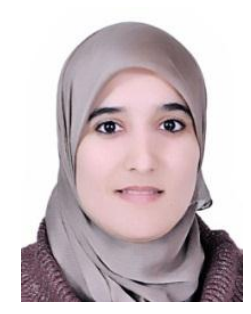

Hanane El Basri is currently in charge of the IT department at the Beni-Mellal regional court of auditors, Morocco, North Africa. She received her Master degree in biomedical genius (instrumentation and maintenance) from Settat University, Morocco, in 2013. Online learning and, in particular, the modeling of metacognitive aspects, is her main focus. 

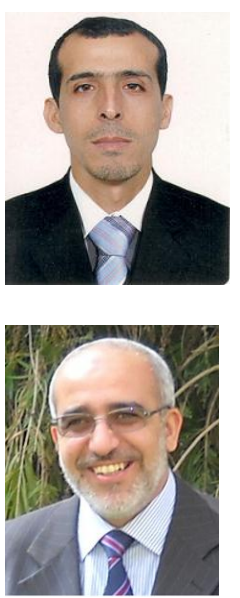

Adil Haddi is currentlycomputer science professorat Berrechid High Technology School, Morocco, North Africa. He received his Ph.D. degree in computer science from Hassan II University, Casablanca, Morocco, in 2009. Its research centers focus on software, datamining, e-commerce and elearning.

Hakim Allali is currently professor of computer science at Faculty of Sciences and Technologies of Hassan 1st Universityof Settat in Morocco and director of LAVETE (watch laboratory of emerging technologies). He is executive manager and founder ofSettat IT Learning Campus.

He received his Ph.D degree in nuclear instrumentation from Claude Bernard Lyon I University, France, in 1993 and the "docteur d'état" degree in surface analysis, modeling and simulation from Hassan II University, Casablanca,Morocco, in 1997.

$\mathrm{He}$ is particularly interested in technology enhanced learning, modeling, image processing and computer networking. 